\title{
The pros and cons of inclusive education from the perceptions of teachers in the United Arab Emirates
}

\author{
Anati, Nisreen $\$ \\ Faculty of Education, Al Ain University of science and Technology, UAE (nisreenanati@yahoo.com)
}

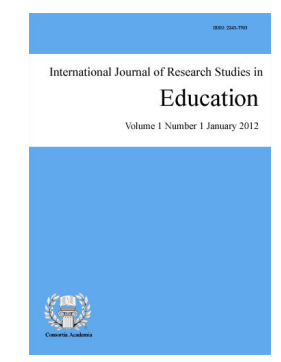

ISSN: 2243-7703 Online ISSN: 2243-7711

OPEN ACCESS

\section{Abstract}

The United Arab Emirates has always been keen to integrate students with special needs in mainstream classrooms. This study explores teachers' attitudes toward the inclusion of children with disabilities in the UAE mainstream schools. It also provides a basic background about the present types of programs and services offered within the UAE schools with respect to individuals with special needs. The main findings of this study which targeted 56 teachers who are involved in teaching students with disabilities in UAE private and public inclusive schools indicated that the participating teachers agreed in principle with the goals of inclusion, however, they were generally unsatisfied about the current practices of inclusion in their schools. These teachers reported that their schools have insufficient allowance for special equipment, resources and services; a limited number of certified special education personnel; a lack of proper training for teachers in mainstream classrooms, and a lack of clear guiding policies available in schools to deal with inclusion issues, even the senior-level administrators are not sufficiently knowledgeable with inclusion practices. Further, these teachers expressed common concerns such as teachers' time taken away from the rest of the students, class size, and safety of children with special needs. Such teachers' concerns might be justified as inclusion is relatively a new educational philosophy practiced in the country.

Keywords: special education teachers; inclusion; UAE special education; students with disabilities 


\section{The pros and cons of inclusive education from the perceptions of teachers in the United Arab Emirates}

\section{Introduction}

A variety of legislations and laws have been released in different nations to ensure a fair participation of students with disabilities in mainstream schools. However, there is a great debate among educators on the extent and nature of including students with disabilities in mainstream schools. According to Friend and Bursuck (2002), three major beliefs were proposed as a result of this argumentative issue among educators to include students with disabilities in mainstream schools: restricted belief (resists inclusion); least restricted belief (allows inclusion under certain conditions); unrestricted belief (accepts inclusion with no or few restrictions). Integrating students with disabilities in regular classrooms is a relatively recent educational philosophy that aims at protecting the right of education for all society members, and it ensures that no child with disability is left behind. Although inclusion is highly supported by many educators, many teachers, educators and policy makers described several challenges that are in the way. Supporters and opponents of inclusion can present research-based reasons for accepting or rejecting the inclusive educational philosophy. They hypothesized that inclusion may have negative or positive impact on teachers, students with disabilities, and normal students.

\subsection{Opponents of inclusion}

Opponents of inclusion noted that classroom management is harder because of the addition of more students, students with disabilities were "monopolizing an inordinate amount of time and resources and, in some cases, creating violent classroom environments" (Sklaroff, 1994, p. 7). One additional concern is that students with disabilities may not feel comfortable because they feel that they are different from other students (Sklaroff, 1994). Furthermore, students with disabilities involved in inclusionary teams make small and moderate gains in academic and social settings. Teacher time is taken away from the other students in the inclusive classroom. Some teachers lack the training, resources and other necessary supports to teach students with disabilities. Teachers have to take more time when planning lessons in order to adapt the lesson to the student or students with special needs (Baker, Wang, \& Walberg, 1995; Cohen, 1994; Tornillo, 1994; Lieberman, 1992). According to Skrtic (1991), "the non-adaptability of regular classrooms and that, since nothing has happened to make contemporary classrooms any more adaptable .... [inclusion] most likely will lead to rediscovering the need for a separate system in the future" (p. 160). A number of research studies report positive attitudes towards inclusion (e.g., Schattman \& Benay, 1992; Stainback \& Stainback, 1990; Friend \& Bursuck, 2002). On the other hand, the following researchers described in their studies the consequences of inclusive education (e.g., Skrtic, 1991; Sklaroff, 1994; Baker, Wang, \& Walberg, 1995; Cohen, 1994; Tornillo, 1994; Lieberman, 1992). There is no clear cut opinion that prefers one view over the other when inclusive education is the core of discussion. Even school teachers had never reached to an agreement on the advantages and disadvantages of inclusion.

\subsection{Proponents of inclusion}

A number of educators hypothesized that it is extremely practical to provide almost all necessary supports for students with disabilities in general classrooms when teachers and school professionals are effectively trained and well prepared to work with such students and related concerns are tackled (Pearman, Haung, \& Mellblom, 1997). Some educators such as Ryan and Paterna (1997) and Wilson (1999) argued that inclusion comprises physical integration, placing students with disabilities in the same classroom as non-disabled peers; social integration, nurturing student relationships with peers and adults; and instructional integration, teaching students based on their needs and not on a predetermined set of curricular standards (as cited in Friend \& Bursuck, 2002, p. 4). In other words, students with disabilities should be fully integrated into general education classrooms as 
The pros and cons of inclusive education from the perceptions of teachers in the United Arab Emirates

long as they are making progress toward the achievement of IEP goals, even if they cannot meet classroom or content demands. Schattman and Benay (1992) found that students with disabilities in an inclusionary setting are exposed to talented teachers, refine new social relationships with the same-age peer group, and experience more quality programs in a regular education classroom. Stainback and Stainback (1990) concluded that inclusion is an appropriate instructional model because students with disabilities are accepted and supported by their peers and other members of the school community while having their educational needs met. Although the educational philosophy of including students with disabilities in mainstream classrooms was proposed and widely accepted, many teachers were concerned.

\subsection{Teachers' attitudes toward inclusion}

Teachers are one of the most important pillars in the education system, therefore it is vital to explore teachers' attitudes toward educational philosophies. According Leatherman and Niemeyer (2007), "teachers form attitudes toward children with disabilities, and ultimately toward inclusion, based on a child's characteristics, the factors in the classroom, and their previous experiences" (p. 24). Consequently, the teacher's attitudes are reflected in their behavior in the classroom and in their interactions with the children. Therefore, the teacher's attitude is an important element in the success of the inclusive classroom. El-Ashry (2009) analyzed several studies that classified teachers' perspectives toward inclusion, and then he classified their attitudes into three categories; positive, negative, and neutral: Some researchers have found that general education teachers were not in favor of inclusion (Coates, 1989; Gersten, Walker, \& Darch, 1988; Larrivee \& Cook, 1979; Semmel, Abernathy, Butera, \& Lesar, 1991).

Similarly, in a review, Scruggs and Mastropieri (1996) found that in ten studies, only 33\% of general education teachers agreed that the general education classroom was the best social or academic placement for students with disabilities, although about two thirds of the participants supported the concept of inclusion. On the other hand, other researchers reported that teachers had more positive attitudes toward inclusion (Avramidis et al., 2000a; Villa, Thousand, Meyers, \& Navin, 1996; Ward, Center, \& Bochner, 1994; York, Vandercock, MacDonald, Heise-Neff, \& Caughey, 1992). In addition, few researchers reported that teachers had uncertain or neutral attitudes (Bennett, Deluca, \& Bruns, 1997; Leyser \& Tappendorf, 2001).

Overall, inclusion is more positive than negative. It teaches society members the concept of fairness and justice. It implies that we are different, but we should celebrate our diversity. As indicated above, previous research has addressed teachers' attitudes toward inclusion in separate studies in various countries. However, there is relatively little research that explores UAE teachers' attitudes toward inclusion. Additionally, there is a limited number of studies that describe the nature and practices of inclusive education in UAE schools. Thus, the current study focuses mainly on the nature of inclusive education that is adopted in the UAE from the perception of UAE teachers. Teachers' attitudes may guide decision makers to plan for better inclusive education.

\subsection{The UAE education system}

The education system of the UAE in comparison to other countries is relatively new. In 1952, there were few formal schools in the country. According to the UAE Ministry of Education, the development of education in the UAE "started effectively in 1962, where the number of schools then was barely 20 schools, in which less than 4000 students studied, mostly male students" (2011, Para. 1). Upon the exploration of Oil and the beginning of development, the UAE focused a lot of attention on education. According to Anati (2012) "The country sat a plan to raise the rate of nationals in the educational sector into $90 \%$ by the year 2020. Several departments were established to ensure the right of education for all without discrimination; women, adults, young youths, and students with special needs are welcomed in the UAE schools" (p. 3). Consequently, a special department was established in the Ministry of Education to cater for children with special needs, to empower them for positive contributions to their communities. Since then, the UAE is dedicating all possible means and efforts to protect the right of education to citizens and its ultimate goal is not to leave any child behind. 
Referring to a data that was released in 2011 by the UAE government, about $25 \%$ of total government expenditure is directed toward education (Abu Dahbi.ae, 2011b). Not surprisingly, the governmental (public) schools are free for citizens and compulsory for students aged 6-12. Non-UAE nationals may attend governmental schools as fee-paying students. Governmental schools are gender-segregated, but private schools are co-educational. It is worth mentioning here also that the UAE Ministry of Education is responsible for all levels of government schooling, as well as supervision of the private sector. Private schools at all levels must be licensed by the Ministry and their programs accredited. There is also a large network of private schools operating at all levels on a fee-paying basis (Abu Dahbi.ae, 2011b). In other words, education is a right for every citizen in the country.

\subsection{Special needs education}

People with special needs are found in the general population of the local people of the UAE who are of Arabic descent. According to Bradshow (2004), it is difficult to estimate the percentages in each of the usual special needs categories (e.g. Autism or Cerebral Palsy) since there is no central data collection agency. Evidence would suggest that "the percentage of people with disabilities in the UAE is similar to the worldwide average, i.e. 8-10 percent of the population" (Bradshow, 2004, p. 51). Federal Law No. 29 of 2006 is "the first law to be issued in UAE to protect the rights of people with special needs" (Abu Dhabi Government, 2011, para. 1). For the most part, article 13 of the same law (Law No. 29 of 2006) matches the universal policies and merits of successful inclusion. It emphasized that the UAE Ministry of Education shall be committed to secure the complete participation of students having disabilities in mainstream schools (Abu Dhabi.ae, 2011a). According to the UAE Minister of Education, "Inclusive education means that all students in a school, regardless of their strengths or weaknesses in any area, become part of the school community" (Hassan, 2008, p.8). Additionally, the UAE Ministry of Education released a School for All or General Rules for the Provision of Special Education Programs and Services guidebook in 2010 in collaboration with the UAE Ministry of Social Affairs, with information and rules about special needs education in the UAE. The handbook also includes certain sections about the country's philosophy toward inclusive education.

Since 2008, the UAE Ministry of Education maximized the efforts to include a great number of students with disabilities into public and private schools. It was posted on ADEC's official website on 1/3/2010 "a total of 173 students with special needs have been integrated into Abu Dhabi's mainstream schools" (Tahnoon, 2011, para. 5). The available data indicated that the number of inclusive schools in the country is increasing. In a major restoration of special education policy, the Ministry of Education published that "it is to develop special needs programs in 110 public schools" (Lewis \& Shaheen, 2010, para. 1). Private schools will also be required to accept children with mild and moderate disabilities, though they will be permitted to charge higher fees to fund the development of their own special education programs. The General Secretariat Executive Council Emirate of Abu Dhabi reported that many students from Abu Dhabi Rehabilitation and Care Center for People with disabilities have been integrated into public schools during 2010. In addition to 23 students who had no previous schooling, while 15 students have been integrated into higher education institutions (Lewis \& Shaheen, 2010). The available data about the enrollment rate of students with disabilities in mainstream schools is increasing, but it is relatively low.

The concept of inclusion is highly received by UAE leaders and policy makers and is considered an appropriate instructional model because students with disabilities are accepted and supported by their peers and other members of the school community while having their educational needs met. Paradoxically, a plethora of personnel in inclusive schools reports some challenges that face them. Mainly teachers complain about the fact that their schools and staff were not "well prepared" to include students with disabilities in their regular classrooms. As a result, it became my purpose to carry out this qualitative study to explore the attitudes of UAE teachers toward the philosophy of inclusive education in the country. Additionally, I became interested in describing the nature of inclusive education in UAE mainstream schools. 


\section{Method}

\subsection{Participating teachers}

The sample targeted 56 teachers who were randomly selected to participate in this study. These teachers were involved in teaching students with disabilities, and their schools adopted the inclusive educational philosophy. All expect three teachers in this sample were Muslim-Arabs, Arabic was their first language and English was their second language. Only three teachers were non Arabs with English tongue. About $70 \%$ of the teachers in this sample were general classroom teachers, and the rest (30\%) are special needs education teachers. These teachers served in either public or private schools with a working experience that ranges between 5 and 15 years. The fifty-six teachers accepted to respond to the researcher-developed questionnaire.

\subsection{Data collection instrument}

The main data collection instrument used in this study was a bilingual English-Arabic survey, developed by the researcher to explore teachers' attitudes toward inclusive education in UAE schools. The participant teachers would select the language of their preference. The responses expected were identical for both languages. The survey discussed seven general issues about inclusion in UAE schools. Each question had a number of choices to select from. The questions covered the following issues: kinds of available disabilities; types of accessible leaning services, equipment, tools, and many others; number of available special education staff; types of special accommodations that are made in the schools' buildings to facilitate the movement of students with disabilities; and the quality and quantity of the professional development courses or training programs that are offered for mainstream teachers. The last and the most important question in the survey was an open-ended question which required the participating teachers to reflect on their overall perspective toward inclusion as an educational philosophy. The respondents had to specify why they "agree" or "disagree" with the philosophy of including students with disabilities in mainstream classrooms. The survey contained enough blank space to allow participants to freely respond to the open-ended questions.

\subsection{Procedure}

\subsubsection{Obtaining an IRB approval}

An application had been submitted to Abu Dhabi Education Council (ADEC), to allow the researcher to carry out a survey of teachers who teach in inclusive settings. An IRB approval was obtained from ADEC to survey teachers in any of the participating schools. Typically, the Council sent a memo to the targeted schools requesting them to cooperate with the researcher upon request. The next step was inviting teachers to participate in this study. Fifty-six teachers were randomly selected to respond to the researcher-developed questionnaire. All teachers were assured that participation was non-compulsory, and they signed consent forms. No incentives were presented.

\subsubsection{Questionnaire distribution}

Once the targeted schools received a memo from ADEC- requesting them to allow the researcher to conduct the survey in their schools, and after an IRB approval from Abu Dhabi Education Council (ADEC) was obtained, the researcher would invite teachers to voluntarily participate in this study. Upon receiving their acceptance to answer the survey, the researcher would visit their schools in order to answer the survey. All respondents could read and answer the questionnaire in 20-30 minutes. The participating teachers would select the language of their preference; some teachers responded in Arabic while others responded in English. The responses expected were identical for both languages. 
The researcher compiled the answered surveys and classified them into two groups: filled in English language and filled in Arabic language. The data were examined, categorized, and consolidated using the evidence from the filled out questionnaires. The phase of data analysis was designed to reduce the data into "manageable chunks" and allow interpretation of the data as the researcher formulated meaning and insights from the participants' responses to the open-ended questions. The surveys were analyzed for themes as they evolved from the written responses. Then, the data were analyzed qualitatively in four major steps of data translation: (1) counting and analyzing the responses using designed templates; (2) coding; (3) separate analysis of individual and groups of questions; and (4) synthesis, interpretation, and discussion of results. To investigate the responses drawn from the questionnaire, a table was made for each question to count the number of responses placed next to each item. For example, the stem was, "Did you receive any kind of professional training?", the researcher will count the number of positive responses and the number of negative responses and then draw a conclusion on the accessibility of training in the targeted schools. This process of placing classified data into tables facilitated the process of data analysis. For data interpretation, a separate analysis of individual and groups of questions was made. The units of meaning were compared with each other and subsequently grouped with similar units of meaning. For instance, teachers' attitudes toward inclusion whether received negatively or positively by the participants were also recorded and interpreted.

To enhance reliability and internal validity, appropriate sampling techniques were used and build a trail of evidence (hard copies of the answered surveys with raw data, schedules of schools' visits, electronic messages with respondents, data reduction and data construction products, soft copies of tables created for data analysis). The data analysis procedure was repeated three times by the researcher. The targeted respondents were randomly selected from the participating schools. The questionnaire went through multiple revisions by the researcher and other specialists in the field of special education. A bilingual Arabic-English questionnaire was distributed as some of the teachers' first language was either Arabic or English.

\section{Results}

The main goal in undertaking this study was to explore teachers' attitudes toward the inclusion of children with disabilities in UAE mainstream schools. The study also describes the nature and practices of inclusive education in UAE schools. The core question in the survey was the last question where the teachers had the freedom to reflect on the pros and/or cones of inclusion based on their teaching experiences. Additionally, they were asked to describe the availability of learning resources and services in their schools; the availability of qualified teachers and school professionals in their inclusive settings; the availability of school services and accommodations designed to facilitate the mobility of students with disabilities; and the accessibility of professional development courses and training programs for staff to improve their experiences to fit in inclusive settings. It can be interpreted from the data obtained from the survey that extra efforts are highly needed to plan for more flourishing inclusive settings.

\subsection{Attitudes and aspirations}

Interestingly, when the participating teachers were asked to reflect on their overall attitude toward the philosophy of inclusive education, the majority of the respondents agreed in principle with this educational philosophy to be implemented in their schools. Nevertheless, all participating teachers were more likely to agree with inclusive education when: (1) The UAE Ministry of Education endorse ongoing specialized training for teachers and other personnel to develop professionally; (2) appoint a team of specialized professionals to deal with inclusive matters; (3) build warm learning environments by emphasizing the values of diversity among students with and without disabilities and in the whole society; (4) equip schools with all necessary developed learning tools, equipment, and electronic services; (5) make necessary adaptations and accommodations to the whole school building to facilitate the mobility of students with disabilities. Once these suggestions are met, the 
UAE teachers will enjoy the values and merits of inclusive education.

The results also indicate that the participants' positive attitudes were influenced by their previous experiences with children who have disabilities. These three teachers felt that teaching in an inclusive classroom had been a positive experience because they had had actual hands-on experiences with children with disabilities and had found successful strategies to work with them. These teachers encouraged interactions among children with and without disabilities in their classrooms, which supports a positive environment for inclusion.

\subsection{The nature of inclusive education in the participating schools}

In regard to the number of students included in mainstream schools, data showed that the number of students ranged from three to seven in each school. It is relatively a small number; however, the number is increasing every year since UAE had adopted the philosophy of inclusion in 2006. It was reported in the Al Manal specialized magazine that the UAE Ministry of Education works endlessly to "adjust 600 schools [to become inclusive schools], which represents $62 \%$ of the population [schools], in the coming three years" (Al Manal, 2011, para. 2). This attitude of including a small number of students with disabilities in mainstream schools is consistent with other studies that described inclusion in Egypt, Jordan, and Palestine; (Alghazo, Dodeen, \& Algaryouti, 2003; Gumpel \& Awartani, 2003; Romi \& Leyser, 2006) they reported that these Arab countries implemented inclusion in a limited number of schools at the experimental levels, later on, the number would be increased gradually.

According to the participating teachers, the UAE inclusive schools used a continuum of educational placements ranging from the highly integrated setting of the general classroom to the highly segregated setting where instruction is delivered in special education classrooms or resource rooms. Few or no special education professionals were employed in the participant schools as the regular teachers were usually the only personnel who were in charge of helping and teaching their special needs students. None of the schools in this sample employed audiologists, occupational therapists, or recreational therapists; however, they might be available upon request. Sixteen schools indicated that itinerant speech-language pathologists may visit schools on a regular basis (once a week) or upon request. The same applies to counselors who may be consulted if needed. As for the following professionals: psychologists and social workers, they were usually available in each school in the UAE, and they had a share in the inclusion process. In respect to the kinds of disabilities, the data drawn from the questionnaire indicated that these UAE schools mainly included students with mild and moderate disabilities. None of the respondents reported the existence of the following severe disabilities in their schools: traumatic brain injury (TBI); multiple disabilities; developmental disabilities; deaf-blindness; and mental retardation.

With regards to the professional development training, data drawn from the questionnaire indicated that almost two thirds of the participants received some training. On the other hand, the mainstream teachers indicated that they had not taken the necessary training to facilitate their roles as teachers in inclusive schools. In many cases, participating teachers were unsatisfied about the short training sessions that they had received. Specialized intensive courses and training programs on the proper care for students with disabilities were requested.

Concerning the accommodations for the physical environment, the respondents reported that their schools' buildings have ramps for wheel chairs. No other accommodations were described by the participant teachers. The rest of the respondents in this sample described that their schools were not really designed to include students with disabilities. Concerning the accessibility of developed tools and equipment, data showed that they are very limited in these schools. When participating teachers were asked to identify some of the tools, equipment, or services existed in their schools, they listed the following: FM, I Pad, AirWriter, large screen TV, Solo liberty low vision aids, and various manipulatives such as ORT stories, blocks, balls, play dough, and many others. Table 1 below gives an indication of the quality and quantity of the learning tools and equipment available in the participating schools. 


\section{Table 1}

Tools and equipment

\begin{tabular}{lc}
\hline \multicolumn{1}{c}{ Learning Tools \& Equipment } & Accessibility in Schools \\
\hline Data Shows & 30 schools \\
Special laptops & 4 schools \\
Smart Boards & 6 schools \\
Portable Magnifiers & 6 schools \\
Perkins Braille & 4 schools \\
Electronic Magnification Kits & 6 schools \\
Talking calculator & 4 schools \\
Tactile globe & 2 school \\
Derbi Share Language Test Kit & 2 school \\
Braille Printers & 2 school \\
\hline
\end{tabular}

\section{Discussion}

In respect to the teachers' overall perspective toward the concept of inclusion, data interpreted from the questionnaire that was directed to 56 teachers in UAE inclusive schools indicated that they agree in principle with the purposes of inclusion, but many do not feel prepared to work in inclusive settings. This attitude is consistent with other teachers' feeling as reported in previous studies. The chief findings are that teachers are not rejecting the goals of inclusive education, but many are not ready to work in inclusive schools (Mastropieri \& Scruggs, 2000; Hines \& Johnston, 1997, as cited in Anati, 2012, p. 8). Additionally, the participating teachers described a number of factors that made them less satisfied about the current practices of inclusive education in their schools. The following section covers some of the raised matters.

Responses drawn from the questionnaire that was directed to teachers in UAE inclusive schools indicated that the country doesn't follow a unified model of inclusive education. For example, the teachers reported that the educational placements ranging from the highly integrated setting of the general classroom to the highly segregated setting where instruction is delivered in special education classrooms and resource rooms. Although teachers were not very comfortable with the placement policies in their schools, they admit that the type and severity of enrolled students' disabilities control schools' decisions in this regard. Indeed, similar worries were raised by teachers in other research studies. For instance, El-Ashry (2009) found in his study that many Egyptian teachers claimed to support inclusion. However, these teachers believed in the importance of maintaining separate settings based on the students' academic performance and based on the severity of students' disabilities. Special education researchers and educators proposed full or partial placement in general classrooms based on student's special needs and disability status (Salend, 2005; Friend \& Bursuck, 2002).

The majority of the teachers in this study agreed that it would not be practical to include students with severe disabilities as they need special care and attention by specialists in the field of inclusive education. This belief may justify the absence of students with severe disabilities in the participating schools in the present study. This finding affirms the previous research results that schools are more inclined to include students with minor and mild disabilities than students with more severe intellectual and emotional and behavioral disabilities (El-Ashry, 2009; Wladron \& McLeskey, 1998; Ward, Center, \& Bochner, 1994). Researchers in these studies confirmed that there is a common belief among mainstream teachers that students with mild disabilities require less modification of curriculum and instruction (Mastropieri \& Scruggs, 2000). It is reasonable for UAE schools, which had not implemented inclusion for long, to include students with minor disabilities until they become competent to include students with mild or severe disabilities.

Generally speaking, when it comes to training and professional development, the majority of the teachers who participated in this study were disappointed about the offered trainings. Although there is evidence that positive attitudes about inclusion correlate with feelings of being well prepared (Mastropieri \& Scruggs, 2000; Bender, Vail, \& Scott, 1995), all teachers in this study reported a lack of confidence and unpreparedness to teach 
The pros and cons of inclusive education from the perceptions of teachers in the United Arab Emirates

in inclusive classrooms as they did not receive proper training to teach in inclusive classrooms. A number of the participating teachers described, "We attended few workshops or participated in short training sessions which did not necessarily prepare us to teach in inclusive settings". These findings are consistent with those of other studies conducted in other Arab countries. For example, Alghazo, Dodeen, and Algaryouti (2003) found that Jordanian teachers, in general, are concerned about teaching in inclusive settings for the lack of professional development training to teach in inclusive environments. Similarly, Palestinian and Egyptian Arab teachers reported anxious attitudes toward inclusion at both in-service (Gumpel \& Awartani, 2003) and pre-service (El-Ashry, 2009; Romi \& Leyser, 2006) levels due to their limited expertise to teach students with different disabilities.

On the other hand, several studies affirmed the constructive impact of special education coursework and professional training in relation to teachers' perspectives toward inclusion (as cited in El-ashry, 2009; Carroll et al., 2003; Scruggs \& Mastropieri, 1996; Shade \& Stewart, 2001; Shippen, Crites, Houchins, Ramsey, \& Simon, 2005). Moreover, few regular teachers in this study pointed out that the structure of their general education program did not include a single course that introduces them to the theories and practices of teaching students with disabilities. It is necessary that UAE undergraduate programs consider including courses on teaching exceptional learners in inclusive settings. In a study by Bender, Vail, and Scott (1995) a positive correlation was found between teachers' attitudes and the number of courses taken in teaching students with disabilities. The study also suggested that the more coursework in the field of special education, the student teachers receive, the more they become aware of techniques for successful inclusive practices and experiences.

When it comes to educational resources, equipment, and services, data drawn from the questionnaire designate that there is an urgent need to make such necessary things more accessible in the inclusive schools. Teachers who took part in this study come to an agreement with other teachers who participated in previous studies, that the absence of appropriate materials and equipment in inclusive schools is an obstacle that impede teachers' attempts to meeting the goals of inclusive education (Alghazo, Dodeen, \& Algaryouti, 2003; El-Ashry, 2009). Moreover, the majority of the schools in this sample were not efficiently designed to facilitate the movement of children with exceptional disabilities. Almost all teachers in this study described the availability of ramps for wheel chairs as an example of accommodations made in their schools to facilitate the physical movement of students with disabilities; no other accommodations were mentioned by the respondents. On the other hand, previous research studies documented the relationship between successful inclusion and efficient accommodations in school's physical environment (Salend, 2005; Mastropieri \& Scruggs, 2000; Salend \& Duhaney, 1999). It is worth mentioning here that the UAE is planning to build new schools which particularly designed to meet the physical needs of students with disabilities.

Not surprisingly, a number of the participating teachers were hesitant at the beginning to work in inclusive schools. Specifically, they were worried because the UAE society is generally not accepting them as teachers of students with disabilities, even classmates are not aware enough of the circumstances of studying with peers with disabilities. This attitude might be attributed to the fact that inclusion is a relatively new phenomenon and it is less widely practiced in the Arab countries as compared to Western countries like the US, Germany, and Canada. In their cross-cultural study, Leyser and colleagues (1994) found that teachers in the United States and Germany expressed the most positive attitudes toward inclusion. Extra efforts are needed in this direction, further attempts should target parents, learners, society members to accept each other and celebrate our diversity.

\section{Conclusion}

This study explores a host of factors that might shape the inclusive education in UAE schools. It also describes the present types of programs and services offered within the UAE schools with respect to individuals with special needs. Most importantly, a sample of in-service teachers' attitudes towards the integration of children with disabilities into mainstream schools in Abu Dhabi has been discussed. Interestingly, the participating teachers in this study agreed in principle with the idea of inclusive education as it reserves the right 
Anati, N.

of education for all learners regardless of their disabilities. On the other hand, these teachers were uncomfortable to teach in inclusive setting as they did not possess solid knowledge and expertise in the field of inclusive education. Furthermore, they reported that there is a lack of systematic procedure to plan, instruct, assess the learning- teaching process in the inclusive schools, even at the level of senior-level administrators there is a lack of confidence to proceed on and follow up issues related to inclusion. Additionally, the participating teachers expressed a lack of funding for resources, equipment, and service to facilitate the teaching-learning process in inclusive classrooms. Worst of all, they described a lack of understanding or awareness among peers and society members concerning the challenges that may encounter them in inclusive environment.

As the country continues its spectacular period of change as a nation, changes in the education of children with special needs will occur at a rapid rate. Although inclusive education in the UAE still at the experimental level, it would be insightful to study how students with and without disabilities accept each other in the inclusive classroom. This would be an important study because teaching strategies that utilize peer assistance are integral part of the inclusive settings. Additionally, it would be of great value to explore how parents of children with and without disabilities receive the principles of inclusive education and how parents' perspectives may have an impact on their own children's perceptions to learn in inclusive settings.

\section{References:}

Abu Dahbi.ae. (2011a). Federal Law No. (29) [Service Topics file]. Retrieved from http://www.abudhabi.ae/egovPoolPortal_WAR/appmanager/ADeGP/Citizen?_nfpb=true\&_pageLabel= $\underline{\text { P1200125611281857352633\&did=231072\&lang=en }}$

Abu Dahbi.ae. (2011b). Abu Dahbi Education System [Service Topics file]. Retrieved from http://www.abudhabi.ae/egovPoolPortal_WAR/appmanager/ADeGP/Citizen?.nfpb=true\&_pageLabel= p19654\&lang=en

ADEC. (2010). ADEC organizes a training program on the use of special needs equipment [Press Release file]. Retrieved from http://www.adec.ac.ae/English/Pages/PressRelease.aspx

Al Manal 251st. (2011, February 28). News. Al Manal Magazine, 251. Retrieved from http://www.schs.ae/news/newsDisplay.aspx?NewsID=120

Alghazo, E. M., Dodeen, H., \& Algaryouti, I. A. (2003). Attitudes of pre-service teachers towards persons with disabilities. College Student Journal, 37(4), 515-522.

Anati, N. (2012). Including students with disabilities in UAE schools: A descriptive study. International Journal of Special Education, 27(2), 1-9.

Baker, E. T., Wang, M. C., \& Walberg, H. J. (1995). Synthesis of research: The effects of inclusion on Learning. Educational Leadership, 52(4), 33-34.

Bender, W. N., Vail, C. O., \& Scott, K. (1995). Teachers' attitudes toward increased mainstreaming: Implementing effective instruction for students with learning disabilities. Journal of Learning Disabilities, 28, 87-94. <http://dx.doi.org/10.1177/002221949502800203>

Cohen, O. (1994, April 20). Inclusion should not include deaf students. Education Week, 35.

El-Ashry, F. (2009). General education pre-service teachers' attitudes toward inclusion in Egypt. (Doctoral dissertation). Retrieved from http://etd.fcla.edu/UF/UFE0024244/elashry_f.pdf

Friend, M., \& Bursuck, W. D. (2002). Including students with special needs: A practical guide for classroom teacher (3rd ed.). USA, Boston: Allyn \& Bacon.

General Secretariat Executive Council Emirate of Abu Dhabi. (2010). ADEC Provides educational equipments [Government News file] Retrieved from http://gsec.abudhabi.ae/Sites/GSEC/Navigation/EN/MediaCentre/government-news,did=153746.html

Gumpel, T., \& Awartani, S. (2003). A comparison of special education in Israel and Palestine: Surface and deep structures, Journal of Special Education, 37, 33-48.

$<$ http://dx.doi.org/10.1177/00224669030370010401>

Hassan, H. (2008). Inclusion in the UAE [PDF document]. Retrieved from 
The pros and cons of inclusive education from the perceptions of teachers in the United Arab Emirates http://www.ibe.unesco.org/fileadmin/user_upload/Policy_Dialogue/48th_ICE/Presentations/IBE_ICE_ Workshop_3B_Presentation_EN_Hanif_Hassan_Nov08.pdf

Hines, R. A., \& Johnston, J. H. (1997). Inclusion. In J. L. Irvin (Ed.), What current research says to the middle level practitioner (pp. 109-120). Columbus, OH: NMSA.

Lewis, K., \& Shaheen, K. (2010, May 21). Schools told to make room for special needs pupils. The National. Retrieved from http://www.thenational.ae/news/uae-news/education/schools-told-to-make-room-for-special-needs-pupil s\#

Leyser, Y., Kapperman, G., \& Keller, R. (1994). Teacher attitudes toward mainstreaming: A cross cultural study in six nations. European Journal of Special Needs Education, 9, 1-15. <http://dx.doi.org/10.1080/0885625940090101>

Lieberman, L. M. (1992). Preserving special education...for those who need it. In W. Stainback, \& S. Stainback (Eds.), Controversial issues confronting special education: Divergent perspectives. Boston: Allyn and Bacon.

Mastropieri, M. A., \& Scruggs, T. E. (2000). The inclusive classroom: Strategies for effective instruction. Upper Saddle River, NJ: Prentice-Hall.

Ministry of Education. (2011). Education in the UAE. Retrieved from http://www.moe.gov.ae/English/Pages/UaeEdu.aspx

Pearman, E. L., Haung, A. M., \& Mellblom, C. I. (1997). The inclusion of all students: concerns and incentives of educators. Education and Training in Mental Retardation and Developmental Disabilities, 32, 11-20.

Romi, S., \& Leyser, Y. (2006) Exploring inclusion pre-service training needs: A study of variables associated with attitudes and self-efficacy beliefs. European Journal of Special Needs Education. 21(1), 85-105. $<$ http://dx.doi.org/10.1080/08856250500491880>

Ryan, S., \& Paterna, L. (1997). Junior high can be inclusive: Using natural supports and cooperative learning. Teaching Exceptional Children, 30(2), 36-41.

Salend, S. J. (2005). Creating inclusive classrooms: Effective and reflective practices for all students (5th ed.). Upper Saddle River, New Jersey, NJ: Pearson Prentice Hall.

Salend, S. J., \& Duhaney, L. M. G. (1999). The impact of inclusion on students with and without disabilities and their educators. Remedial and Special Education, 20, 114-126. <http://dx.doi.org/10.1177/074193259902000209>

Schattman, R., \& Benay, J. (1992). Inclusive practices transform special education in the 1990's. The School Administrator, 49(2), 8-12.

Scruggs, T. E,. \& Mastropieri, M. A. (1996). Teacher perceptions of mainstreaming/inclusion, 1958-1995: A research synthesis. Exceptional Children, 63, 59-74.

Sklaroff, S. (1994, January 12). A.F.T. urges halt to 'full inclusion' movement. Education Week, p. 7.

Skrtic, T. M. (1991, May). The special education paradox: Equity as the way to excellence. Harvard Educational Review, 6(2), 148-206.

Stainback, W., \& Stainback, S. (1990). Support networks for inclusive schooling. Baltimore: Brookes.

Tahnoon, N. (2011). Special needs students [News Catalog file] Retrieved from http://www.adec.ac.ae/NewsCatalog/Forms/DispForm.aspx?ID=110

Tornillo, P. (1994, March 6). A lightweight fad bad for our schools? Orlando Sentinel.

Ward, J., Center, Y., \& Bochner, S. (1994). A question of attitudes: Integrating children with disabilities into regular classrooms? British Journal of Special Education, 21, 34-39. $<$ http://dx.doi.org/10.1111/j.1467-8578.1994.tb00081.x >

Wilson, B. A. (1999). Inclusion: Empirical guidelines and unanswered question. Education and Training in Mental Retardation and Developmental Disabilities, 34, 119-133.

Wladron, N. L., \& McLeskey, J. (1998). The effects of an inclusive school program on students with mild and severe learning disabilities. Exceptional Children, 64, 395-405. 
Anati, N. 